\title{
A THYROID GLAND SHOWING PYRAMIDAL LOBE WITH LEVATOR GLANDULAE THYROIDEA.
}

Sreekanth, T. Mahjabeen Salma, M. Annapurna, Sabah Yaseen

\author{
1. Associate Professor, Department of Anatomy, Shadan Institute of Medical Sciences, Teaching Hospital \& \\ Research Centre, Hyderabad, Andhra Pradesh. \\ 2. Associate Professor, Department of Pathology, Dr. V. R. K. Women's Medical College. Hyderabad, Andhra \\ Pradesh. \\ 3. Professor \& Head, Department of Anatomy, Shadan Institute of Medical Sciences, Teaching Hospital \& \\ Research Centre, Hyderabad, Andhra Pradesh. \\ 4. $\quad 1^{\text {st }}$ Year PG Student, Department of Anatomy, Shadan Institute of Medical Sciences, Teaching Hospital \& \\ Research Centre, Hyderabad, Andhra Pradesh.
}

\author{
CORRESPONDING AUTHOR \\ Dr. Sreekanth, \\ 237/2RT, Vijayanagar Colony, \\ Hyderabad, Andhra Pradesh, \\ E-mail: anatomysreekanth18@yahoo.com \\ Ph: 040-23345429, +91 9848826008
}

\begin{abstract}
The Literature is replete with wide range of common and rare variations of thyroid gland. The presence of pyramidal lobe (accessory lobe) - a rostral directed stalk that results from the retention and growth of the caudal end of thyroglossal duct and fibrous or fibromuscular levator glandulae thyroidea (LGT) arising from its apex are commonly occurring variations. A 50 yrs Old Male Cadaver showed levator glandulae thyroidea with cranio caudal extension from the body of the hyoid bone to the apex of pyramidal lobe which was projecting upwards from the left $3 / 4^{\text {th }}$ of isthmus without any encroachment on the left lobe of the thyroid gland. In the groove clearly demarcating pyramidal lobe from the left lobe, a glandular branch of anterior branch of left superior thyroid artery was seen. It entered the pyramidal lobe inferiorly, just above the lower border of the isthmus.

Just adjacent to the right lobe a small portion of isthmus with prominent and free upper border and lower border is seen. Due its frequent presence it may not be fascinating to the Anatomists but can definitely challenge the skill of operating neck surgeons performing thyroidectomies, lobectomies and isthmusectomies and Otolaryngologists performing tracheostomies ,tracheotomies and laryngotomies. The wide range of variations in the number, size, extent and consistency of the levator glandulae thyroidea (LGT) and pyramidal lobe necessitate the pre operative ultrasonographic examination or scintigraphical images or intense contrast enhancement on CT/MRI scan for total anatomical details enabling relatively a safer surgery.
\end{abstract}

KEY WORDS: (pyramidal lobe) (levator glandulae thyroidea) (thyroglossal Duct anomalies)

INTRODUCTION: A normal thyroid gland is located anterior to trachea and midway between the apex of thyroid cartilage and suprasternal notch. Important neighboring posterior structure include four para thyroid glands situated behind the pear shaped lobes and recurrent laryngeal nerves coursing along trachea. The isthmus connects the lower parts of the lobes. It extends from second and third tracheal rings often higher or sometimes lower. (2) A conical pyramidal lobe often ascends towards the hyoid bone from isthmus or the adjacent part of either lobe 
(more often left). A glandular or fibrous or fibro muscular band, the levator of the thyroid gland (musculus levator glandulae thyroidea) sometimes descends from the hyoid body to the isthmus or apex of pyramidal lobe.

EMBRYOLOGICAL BASIS: It is the first endocrine gland which appears and begins to function at approximately by the end of $3^{\text {rd }}$ month, at which time the first follicles containing colloid become visible. (3) The appearance in the fourth week of embryonic life is as a endodermal nodule at the apex of foramen caecum on developing tongue the nodule descends through the neck at the end of a slender thyroglossal duct which breaks down by the end of $5^{\text {th }}$ week and continues its descent to reach its definitive position by $7^{\text {th }}$ week. The commonest evidence of embryologic thyroid descent is the small pyramidal lobe projecting upwards fr pyramidal lobe projecting upwards from the isthmus more commonly on left than on right side.

MATERIALS AND METHODS: The present variation was observed during the routine Dissection hours for the first year M.B.B.S students, in an embalmed male cadaver aged about 55 years in the Department of Anatomy at Shadan Institute of Medical Sciences Teaching Hospital and Research Centre, Peerancheru, Hyderabad, Andhra Pradesh. The routine dissection instruments such as scalpel, blade, surgical and Anatomical forceps were used. The method of Dissection began with a median incision made from the chin downwards towards the supra sternal notch with a scalpel. A horizontal incision is made along the posterior border of the base of the mandible till the mastoid process and the skin flaps were raised and reflected laterally. Another horizontal incision is given along the upper border of the clavicle. Platysma a subcutaneous muscle which is also reflected along with the cutaneous nerves lying in the superficial fascia of the neck. The supra hyoid and the infra hyoid group of muscles on each side of the median plane are identified. The sternocleidomastoid muscles of both the sides are cut through their origin and reflected upwards, the deeper structures including thyroid gland and trachea are seen. The carotid triangle formed between posterior belly of the digastrics muscle and the stylohyoid (Anterosuperiorly) Superior belly of omohyoid (Anteroinferiorly) and Anterior border of the sternocleidomastoid muscle (Posteriorly) is defined and the contents (The common carotid artery, the internal carotid artery, the external carotid artery, internal jugular vein, vagus nerve, superior laryngeal branch, spinal accessory nerve) are all being identified. From the surface of trachea, fibrous remains of the thymus gland were removed. A portion of the isthmus with the pyramidal lobe of the thyroid gland was seen lying on the trachea rings.

OBSERVATION: During the routine dissection hours of $1^{\text {st }}$ year medical students in the Department of Anatomy a 55 years old male cadaver showed the presence of pyramidal lobe with the levator glandulae thyroidea (LGT). (Fig.1) The pyramidal lobe was arising from the entire glandular part of the left $3 / 4$ th of isthmus (not just from its upper border) more towards the left side (6). There is no lower border seen on the left $3 / 4$ of the isthmus on the left. Adjacent to the right lobe the right $1 / 4^{\text {th }}$ of isthmus showed prominent free upper and lower borders (Fig.2 \& 9). There is a groove clearly demarcating the pyramidal lobe from the left lobe indicating no encroachment of the later by the former (Fig.5) The pyramidal( glandular) branch from the anterior branch of right superior thyroid artery is seen in the groove entering in to it inferiorly just above the lower border of isthmus. (Fig.6) A fibro muscular LGT was seen arising with a broad base from apex of the pyramidal lobe and its narrow tapering fibrous tip 
was extending upto the body of hyoid bone. The anterior branch of the right superior thyroid artery is seen descending along the medial border of the lobe and running over the free upper border of the isthmus and passing behind LGT.

DISCUSSION: The literature is replete with wide range of common and rare variations of thyroid gland. The presence of pyramidal lobe and levator glandulae thyroidea at its apex reaching the body of hyoid bone is a common variation. In the present case the pyramidal lobe was seen arising from the glandular isthmus more towards the left side with inferior extension beyond the lower border with no encroachment over the adjacent left lobe. Ranade AV, (12) after studying 105 cadavers (88 male \& 17 female) reported the presence of pyramidal lobe in $61(58 \%)$ male cadavers. and the same was absent in female cadavers. The levator Glandulae Thyroideae LGT in 52 (49.5\%) cadavers. only two (12\%) female cadavers showed its presence. In the study done by Joshi SD (4) over 90 male cadavers the pyramidal lobe was present in 34 $(37.77 \%)$ cases frequently arising from left lobe and LGT was present in 27 (30\%) of cases cranially attached to the body of hyoid bone. The study of the pyramidal lobe in Bangladeshi people (5) reveled incidence to be $50 \%$ more common in males $(52.1 \%)$ than in females $(41.7 \%)$ commonly situated on left side from the upper border of isthmus with or without encroachment on the adjacent left lobe. In $73.33 \%$ of cases the pyramidal lobe was associated with LGT and only $26.66 \%$ cases it was found independently. Sultana SZ (6) studied the occurrence of LGT with cranio caudal attachment in 60 Bangladeshi people and reported it to be $43.33 \%$. About $92 \%$ of LGT were found attached to the body of the hyoid bone cranially. Only in 2 case the cranial attachment was limited to the oblique line of thyroid cartilage. A very rare variation of LGT muscle with three slips has been reported by Marios Loukas (7)in a 83 year old Caucasian female. Devi Shankar (10) reported bilateral LGT arising from the apices of both pyramidal lobes with agenesis of isthmus.

The knowledge of these common variations enhances the confidence of surgeons while performing tracheostomy [window being created in the anterior wall of trachea to exterior] tracheotomy (opening of trachea) laryngotomy /cricothyroidotomy/coniotomy [opening the larynx] at the crico thyroid membrane, as it is necessary to divide the pretracheal layer in order to expose the isthmus of thyroid gland either to retract it up or down using isthmus hook or divide it after clamping followed by suturing the stumps some times, the procedures are done above or below the isthmus. In this type of case which is reported if the procedure has to be performed above the isthmus then the pyramidal lobe with LGT needs more attention and to be meticulously done. (9) Unilateral total lobectomy and isthmusectomy is adequate for minimal $\leq$ $1 \mathrm{~cm}$ lesion of differentiate thyroid cancer, unilateral thyroid nodule, encapsulated papillary cancers (rare) have a excellent prognosis (13). The most common site of nodule in a multi nodular goiter (MNG) is at the junction of isthmus with one of the lobes (14). Subtotal thyroidectomies employed for nontoxic multi nodular goiter where in at least 6-8 gm of thyroid tissue is left behind as it is difficult to measure some surgeons advocate leaving thyroid tissue as small as tip of little fingers on both sides. Total thyroidectomy is done in cases of aggressive Hurthle cell carcinomas. (14) The wide range of variations in number, size, extent consistency, supra isthmic arterial arcade necessitate the pre operative high frequency ultrasonographic or scintigraphical images or intense contrast enhancement on CT/MRI scan (11) for total awareness of Anatomical details enabling relatively a safer surgery. 
CONCULUSION: The knowledge of these common variations enhances the confidence of surgeons while performing surgeries over the thyroid gland so that unusual situation can be handled with confidence rather than surprise. Having a through Anatomical knowledge about the rare to the most commonly occurring variations is an essential prerequisite for the General Surgeons, ENT surgeons, Face and Neck Surgeons, Plastic Surgeons to improvise their surgical skills.

ACKNOWLEDGEMENT: I wish to thank the towering personality Dr. Sarib Rasool Khan Managing Director of our prestigious Institute for all the Inspiration \& encouragement extended to us.

I Thank Mr. J. George William, Librarian, SIMS for typing the manuscript.

\section{REVIEW OF LITERATURE:}

1. Williams PL, Bannister LK, Berry MM, Collins P, Dison M, Dussek JE, Ferguson MWJ. Grace Anatomy, 38 th Ed, Edinbugh, Churchill living stone 2000, 1891-1897.

2. Mario De Felice and Roberto Di Lauro. Anatomy and development of Thyroid gland. Leslie. J Degroot. J. Larry-Jameson. Endocrinology 5th Edn Vol-2 91 Pg; 1785-1787.

3. T.W. Saddler. Langmans Medical Embryology $11^{\text {th }}$ Edn pg; 278-279.

4. Joshi SD, Joshi SS, Daimi SR, Athavale SA. The Thyroid gland and its variations: a cadaveric study. Folia Morphol (Warsz). 2010 Feb; 69(1): 47-50.

5. Sultana, SZ Mannan, S, Ahmed, MS, Rahman, MM, Khan, MK, Khalil, M. An anatomical study on pyramidal lobe of thyroid gland in Bangladeshi people. Index Medicus for South-East Asia: IMSEAR. Mymensingh Medical Journal. 2008 Jan; 17(1) : 8-13

6. Sultana SZ, Khalil M, Khan MK, Shamim R, Parveen S, Ara ZG. Morphological study of levator glandulae thyroidea in Bangladeshi Cadaver. Mymensingh Med J. 2009 Jul; 18(2) :179-83

7. Loukas M, Merbs W, Tubbs RS, Curry B, Jordan R. Levator glandulae thyroideae muscle with three slips. Anat Sci Int. 2008 Dec; 83 (4) : 273-276.

8. Grace A. Lee MD \& Umesh Masharani, MRCP (UK), Diagnosis and treatment in otolaryngology - Head and Neck Surgery Anil K Lalwani. Section X Thyroid \& Para thyroid; Disorders of Thyroid gland International Edn 2004 Pg: 579 - 598

9. P. Hazarika, D.R Nayak, R Bala Krishnan. Text Book of Ear Nose Throat \& Head \& Neck Surgery. $1^{\text {st }}$ Edn 2007, Tracheostomy Ch: 76 Pg; $724-732$.

10. Devi Sankar K, Sharmila BHANU P, Susan PJ, Gajendra K, Agenesis of isthmus of thyroid gland with bilateral levator glandulae thyroideae. International Journal of Anatomical Variations (2000) 2: 29-30

11. Paul Butler, Adam W.M. Mitchell; Harold Ellis. Applied Radiological Anatomy South Asian Edition 2001 Pg; 96-97.

12. Ranade AV, Rai R, Pai M M, Nayak S R, Prakash, Krisnamurthy A, Narayana S. Anatomical Variations of the thyroid gland: Possible surgical implications. Singapore Medical Journal 2008; 49(10):831.

13. John R Farndon, 0 James Garden, Simon Paterson Brown. Endocrine Surgery $2^{\text {nd }}$ Edn., Gregory P. Saddler Malcom H. Wheeler. The thyroid gland. Chapter 2: Pg; 39-89

14. K. Rajgopal Shenoy. Manipal Manual of Surgery. $2^{\text {nd }}$ Edn., The thyroid gland Pg: 241-271. 


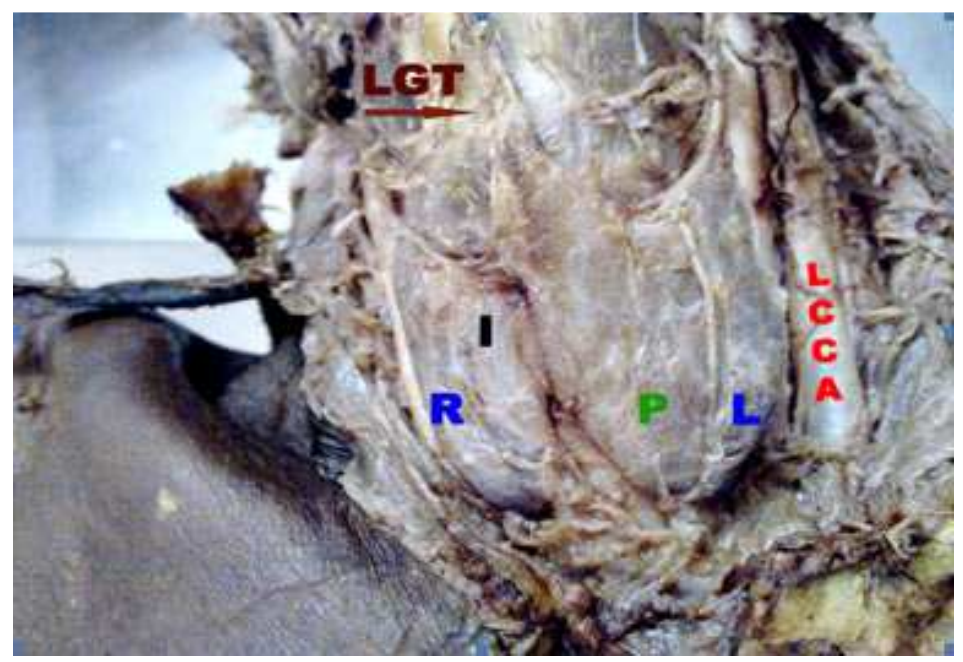

(Fig.1) Anterior View of Dissected Neck showing the thyroid gland. R \& L- right and left lobes respectively. P- Pyramidal lobe,

I- isthmus, LCCA- Left Common Carotid Artery, LGT- levator Glandulae Thyroidea

The pyramidal lobe is seen medial to the left lobe and levator glandulae thyroidea is seen arising from its apex.

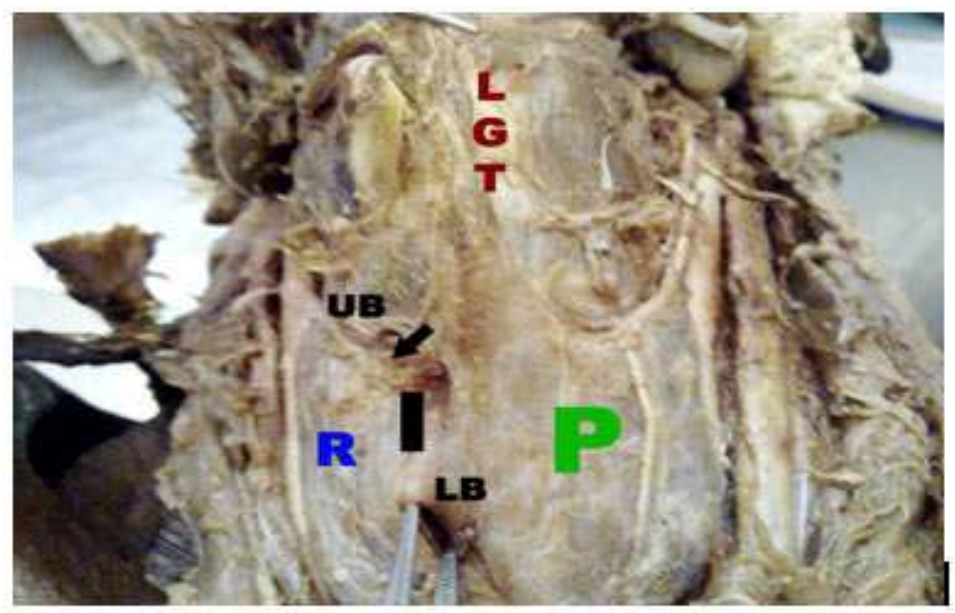

(Fig.2) anterior view of the thyroid gland. UB - Upper border of right $1 / 4^{\text {th }}$ of isthmus. LB Lower border of right $1 / 4^{\text {th }}$ of isthmus. The prominent and free upper and lower borders of the isthmus seen. 


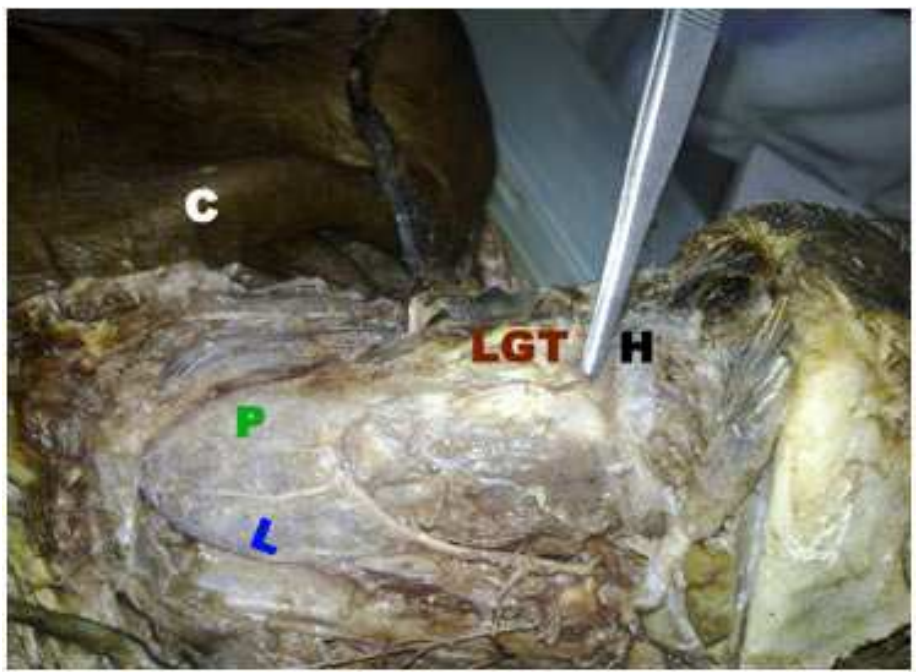

(Fig.3) Supero lateral view of the neck dissection. H - hyoid bone. C - Clavicle The tip of the Levator Glandulae Thyroidea is seen attached to the body of Hyoid bone.

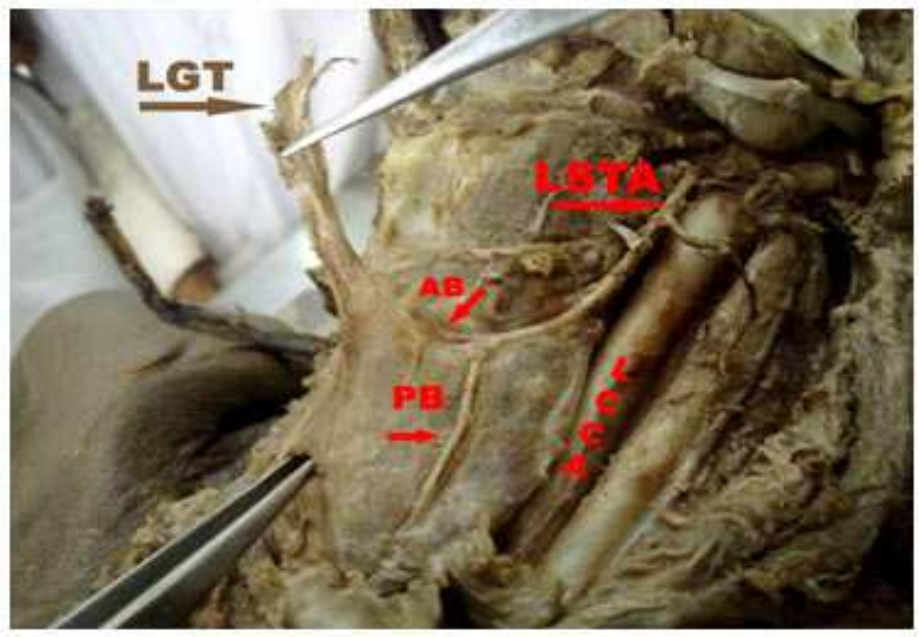

(Fig.4) Left lateral view of neck dissection. AB - anterior branch PB -Pyramidal (glandular) branch LCCA- left common carotid artery LSTA - Left Superior thyroid artery

The tip of LGT is seen cut off from the body of the thyroid. The anterior branch is passing behind the LGT along the upper border of left portion of the isthmus. The pyramidal (glandular) branch is seen arising from the anterior branch of left superior thyroid artery. 


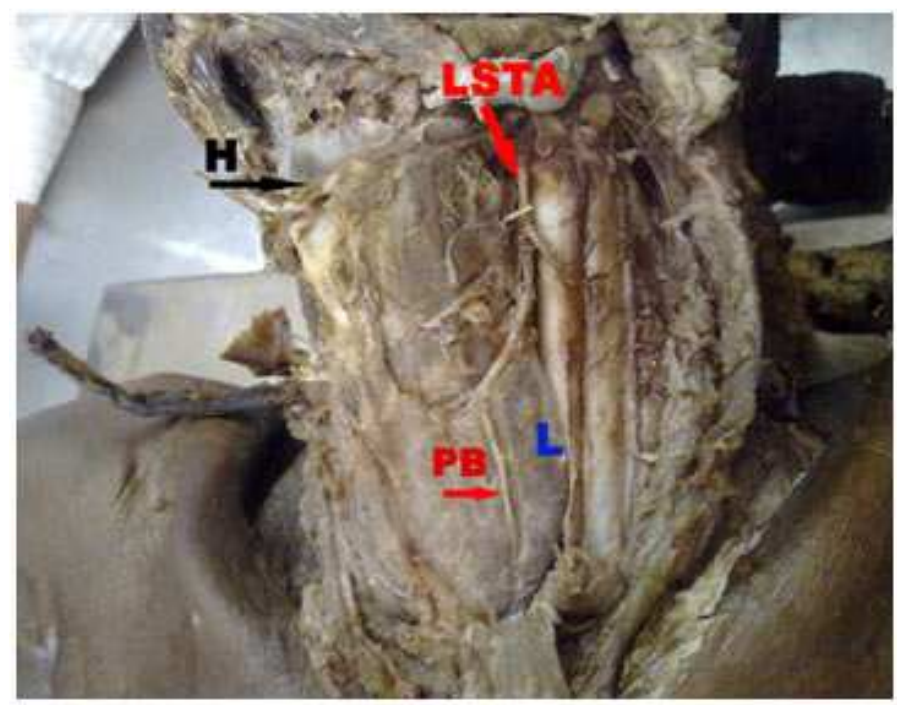

(Fig.5) The groove demarcating the pyramidal lobe from the left lobe is seen indicating no encroachment of the later by the former just by the side of pyramidal (glandular) branch.

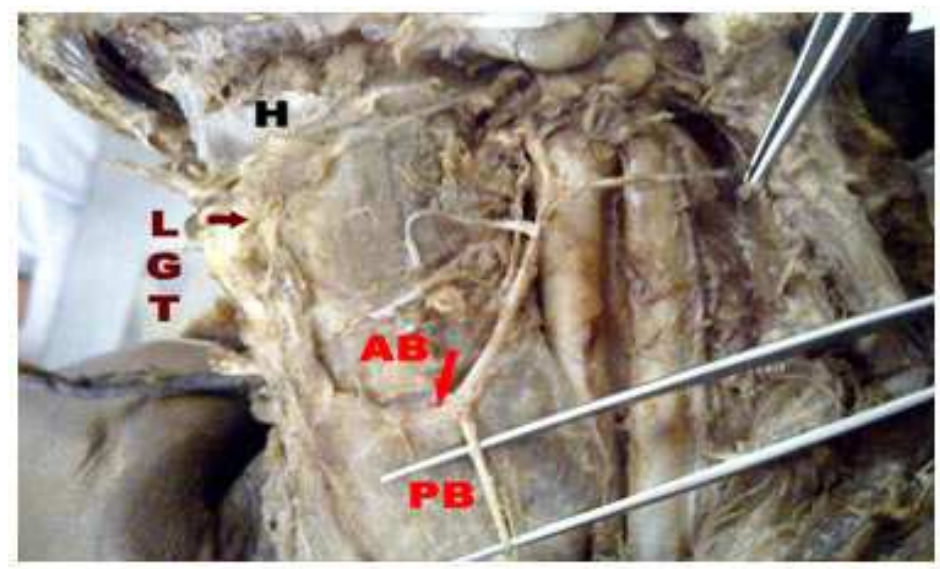

(Fig.6) The PB - Pyramidal branch is shown lifted from the groove in which it was present. 